James F. Mayhew MD, Jeffrey Katz MD CH B, Michael Miner MD, Basil C. Leiman FFA(SA) Ian D. Hall FFARCS

\section{Anaesthesia for the achondroplastic dwarf}

Over the past three years, 36 anaesthetics were administered to 27 patients with achondroplastic dwarfism. Twenty-four patients undenwent craniectomy for foramen magnum stenosis. Sixteen of the operations were undertaken in the sitting position with nine incidents of venous air embolism (VAE), all of which occurred in patients under 12 years of age.

Six major complications occurred: two C-l level spinal cord infarctions, two brachial plexus palsies, one severe macroglossia, and one accidental extubation.

Intravenous access in the small child with achondroplastic dwarfism is made difficult because of the excess, lax skin and subcutaneous tissue.

Airvay management and laryngoscopy were not diffcult and we found that endotracheal tube size was best predicted by the patient's weight and not age.

Blood loss was $38 \pm 9 \mathrm{mg} \cdot \mathrm{kg}^{-1}$ in the prone position $(\mathrm{n}=8)$ and $18 \pm 4 \mathrm{mg} \cdot \mathrm{kg}^{-1}$ in the sitting position ( $\mathrm{n}=$ 16), and was related to the surgical procedure rather than to dwarfism.

Our data indicate that complications are more likely to occur in the sitting position, and that these complications are of a serious nature, and every precaution should be taken to avoid their occurrence.

Key words

ANAESTHESIA: paediatric; SURGERY: neurologic; GENETIC FACTORS: achondroplastic dwarfs.

From the University of Texas Health Science Center at Houston, Houston, Texas.

Address correspondence to: Dr. James F. Mayhew, Department of Anesthesiology, Oral Roberts University/ City of Faith Medical Center, 8181 South Lewis Avenue, Tulsa, Oklahoma 74170-7070.
The achondroplastic dwarfs comprise the most common form of dwarfism seen clinically. The condition is transmitted via an autosomal dominant trait with a high spontaneous genetic mutation rate. The incidence is reported to be one in 26,000 live births. ${ }^{1}$ The basic defect is thought to be a quantitative decrease in the rate of endochondral ossification, ${ }^{1}$ and this, coupled with normal periosteal bone formation, leads to the shorter tubular bones present in achondroplastic dwarfs. This abnormal bone growth is responsible for several potential anaesthetic problems.

The physical characteristics and deformities of achondroplastic dwarfism are well described ${ }^{3,4}$ However, apart from several case reports, little is known about the special anaesthetic problems associated with achondroplasia. ${ }^{3,5}$ Achondroplastic dwarfs characteristically require a number of specific surgical procedures, including suboccipital craniectomy for foramen magnum stenosis, laminectomy for spinal stenosis, and ventricular peritoneal shunts. This need for surgery has resulted in the development of referral centres for specialized care. This is a report of our experience in providing anaesthesia for these patients.

\section{Methods}

We reviewed the anaesthetic records of all patients with achondroplastic dwarfism who received anaesthesia at the Hermann Hospital at the University of Texas Health Science Center, Houston, Texas from December 1982 to June 1985. In view of the abnormal relationship between weight, size, and age in these patients, we were especially interested in which variables could best indicate the appropriate endotracheal tube size. We further looked at airway problems and other complications that occurred during the course of anaesthesia. Blood loss was estimated by adding the volume of blood in the suction trap to the estimated volume on surgical sponges.

Because of the close proximity of the surgical site to the spinal cord, and the pre-existing foramen 
TABLE I Operative procedures

\begin{tabular}{lr}
\hline Suboccipital craniectomy & 24 \\
V-P Shunts & 4 \\
Lumbar laminectomy & 4 \\
Cervical laminectomy & 1 \\
Mastoidectomy & 1 \\
Tendon release & 1 \\
Appendectomy & 1 \\
& 36 \\
\hline
\end{tabular}

magnum stenosis, somatosensory evoked potentials (SEP) were monitored in all patients for suboccipital craniectomy. Stimulating electrodes were placed at the lower limbs (posterior tibial nerve) and upper limbs (median nerve).

\section{Results}

The majority of our patients (22 of 27) were 16 years of age or younger; 16 were males and 11 were females. Twenty-four of our patients presented for suboccipital craniectomy and of these, 22 were children. Sixteen patients had their surgery in the sitting position, the other eight in the prone position. In total, 36 procedures were performed (Table I). Of these 36, 29 were for relief of spinal stenosis at some level. This is the most common problem for which achondroplasts present for surgery.

We found that weight was the best indication of appropriate tracheal tube size in most of these patients (Table II).

Blood loss during surgery in the prone position was $38 \pm 9 \mathrm{ml} \cdot \mathrm{kg}^{-1}$ and $18 \pm 4 \mathrm{ml} \cdot \mathrm{kg}^{-1}$ in the sitting position.

\section{Anaesthetic management}

If patients already had intravenous catheters in place, they received an intravenous induction of anaesthesia with thiopentone (3-5 $\mathrm{mg} \cdot \mathrm{kg}^{-1}$ ). Other patients, all of whom were children, received inhalation inductions with halothane. Once it was established that mask ventilation was possible, a non-depolarizing neuromuscular blocking agent was given to facilitate tracheal intubation. Further doses were used as necessary to maintain muscular relaxation throughout surgery. Anaesthesia was maintained with a combination of isoflurane, nitrous oxide and oxygen, and narcotics as required. Monitoring included an electrocardiograph, precordial and oesophageal stethoscopes, rectal and/or
TABLE II Achondroplastic dwarfs. Endotracheal tube selection

\begin{tabular}{lll}
\hline Age & Weight $(\mathrm{kg})$ & $\begin{array}{l}\text { Endotracheal tube size } \\
\text { ID }-\mathrm{mm}\end{array}$ \\
\hline 4 months & 3.4 & 3.5 \\
7 months & 7.0 & 3.5 \\
10 months & 7.2 & 4.0 \\
10 months & 8.0 & 4.0 \\
10 months & 7.5 & 4.0 \\
11 months & 6.8 & 4.5 \\
12 months & 9.7 & 4.0 \\
18 months & 5.6 & 4.5 \\
18 months & 8.4 & 4.5 \\
2 years & 10 & 4.5 \\
2 years & 11.3 & 4.5 \\
4 years & 12.0 & 5.0 \\
5 years & 6.2 & 4.0 \\
6 years & 21.5 & 6.0 \\
7 years & 22.9 & 6.0 \\
9 years & 21.3 & 6.0 \\
10 years & 23.7 & 6.0 \\
11 years & 29.5 & 6.0 cuff \\
12 years & 30 & 6.0 cuff \\
14 years & 30 & 7.5 cuff \\
15 years & 29 & 6.5 cuff \\
16 years & 29.5 & 6.0 cuff \\
17 years & 36.8 & 7.0 cuff \\
24 years & 54 & 7.0 cuff \\
25 years & 39 & 7.5 cuff \\
34 years & 61 & 7.5 cuff \\
43 years & 64 & 7.5 cuff \\
\hline & & \\
\hline
\end{tabular}

oesophageal temperature probes, an automatic blood pressure monitor, and somatosensory evoked potential monitors. In those patients having surgery in the sitting position, precordial doppler heart sounds and end-expired carbon dioxide levels were also monitored.

Each patient had two peripheral intravenous catheters, an arterial catheter, and a central venous catheter placed.

At the end of surgery, residual neuromuscular blockade was reversed with neostigmine $(0.05$ $\left.\mathrm{mg} \cdot \mathrm{kg}^{-1}\right)$, and atropine $\left(0.02 \mathrm{mg} \cdot \mathrm{kg}^{-1}\right)$. Prompt extubation was achieved in all but three patients (macroglossia and spinal cord infarctions).

\section{Complications}

Complications in the sitting position included two brachial plexus palsies, one severe oedema of the tongue (macroglossia) which required tracheostomy, ${ }^{5}$ nine incidences of venous air embolism and two high spinal cord infarctions (Table III). All 
TABLE III Complications in sitting position

\begin{tabular}{lc}
\hline Complications & Patient age \\
\hline Bilateral brachial plexus palsy & 11 months \\
Bilateral brachial plexus palsy & 11 years \\
Macroglossia & 18 months \\
C-1 Spinal cord infarction & 5 years \\
C-1 Spinal cord infarction & 14 years \\
Venous air embolism (VAE) & 4 months \\
VAE & 12 months \\
VAE & 18 months \\
VAE & 2 years \\
VAE & 2 years \\
VAE & 4 years \\
VAE & 5 years \\
VAE & 6 years \\
VAE & 7 years \\
VAE & 12 years \\
\hline
\end{tabular}

venous air emboli occurred in children 12 years of age or less.

In the prone patients, complications included an accidental extubation, one case with very severe venous bleeding, and one incident of venous air embolism (Table IV).

\section{Discussion}

Our experience indicates that the most common problem seen clinically originates from the high incidence of spinal and foramen magnum stenosis. These patients present with sleep apnoea and nocturnal airway obstruction which is probably related to brain stem compression. ${ }^{6-8}$ Patients with sleep apnoea tend to have apnoeic spells followed by periods of hyperventilation. Therefore, carbon dioxide retention has not been a problem. Most of the patients for suboccipital craniectomy were under 12 years old and pulmonary function was not evaluated. Other problems associated with spinal stenosis include chest deformity and upper cervical myelopathy. 9,10 Some of the patients have such severe spinal stenosis that they present with long tract signs and need decompression to preserve peripheral neurological function.

TABLE IV Complications in prone position

\begin{tabular}{lc}
\hline Complication & Patient age \\
\hline Accidental extubation & 18 months \\
Venous air embolism & 7 months \\
Severe bleeding & 9 years \\
\hline
\end{tabular}

Achondroplastic dwarfs classically have a large protruding forehead, a short maxilla, large mandible, and large tongue and fall into a group that would immediately alert the anaesthetist to a potential problem in airway management. Certainly, these facial features may lead to difficulties in obtaining a seal with a mask. In our experience, however, mask ventilation was not a problem and intubation has been without difficulty. There are two reports of difficult laryngoscopy and endotracheal intubation in the literature ${ }^{3,11}$ and in both cases the difficulty was attributed to an inability to extend the neck. We have not seen this problem in our patients.

We were interested in the relationship between the appropriate endotracheal tube size when compared with patient's age and weight. While most formulae for establishing the appropriate-sized tube are based on age, it is our experience that weight is a far more valuable guide in these patients. Smaller diameter tubes were required in the majority of patients in our series than would have been predicted on an age basis calculation. This is in agreement with the findings of Walts ${ }^{3}$ (Table II).

Because these patients have spinal stenosis it is very important to be able to examine them in the immediate postoperative period. We therefore selected an anaesthetic technique which would allow this to be accomplished. Patients who either had intravenous catheters in place, or were old enough to tolerate them being placed before induction, had intravenous inductions with thiopentone. Anaesthesia was maintained with muscle relaxants, and inhaled isoflurane and nitrous oxide in oxygen. In the younger patients inhalation inductions were conducted with halothane because of the ease with which children accept this technique. Once induction and intubation had been accomplished, isoflurane was substituted for halothane, because it theoretically allows faster recovery. None of the dwarfs showed abnormal response to non-depolarizing muscle relaxants, or other drugs.

These patients tend to have excess skin and subcutaneous tissue, which makes the establishment of intravenous lines more difficult. The placement of peripheral intravenous lines and arterial catheters did not present a significant problem. However, placement of central venous catheters for those in the sitting position proved more difficult. Dwarfs have short necks, and this, associated with 
the difficulty in identifying landmarks, led us to the conclusion that these catheters could best be placed using the internal jugular route. In only one patient were we unable to establish a central line and this patient had surgery in the prone position. Thirteen of 16 patients had internal jugular catheters placed. We found the posterior approach to the internal jugular vein particularly useful in children under three years of age.

While spinal cord or brain stem ischaemia and infarction are not common during surgery conducted in the sitting position, reports do exist of severe ischaemia resulting in spinal cord infarction. ${ }^{12}$ For this reason, it is thought to be good practice to monitor somatosensory evoked potentials so that any change in latency would serve as a warning that the spinal cord perfusion is being compromised. ${ }^{13-15}$ Spinal cord and brain stem ischaemia are thought to be related to extreme flexion of the neck, swelling of the actual neuronal tissue or direct interference with blood supply due to surgical manipulation. We monitored somatosensory evoked potentials in all of our cases. One 14-year-old child, although showing no changes on the somatosensory-evoked potential during surgery, did not wake up normally at the end of the procedure and five hours later was found to have no function distal to the brain stem. Computerized axial tomography performed later confirmed a brain stem infarction. This patient remains quadriplegic. In another patient flaccidity distal to spinal cord level $\mathrm{C}_{1}$ was obvious postoperatively. This patient has regained only minimal function. SEP also failed to reveal abnormality during surgery in this patient.

The two incidents of transient brachial plexus palsy occurred in small children in the sitting position. In both cases the, somatosensory-evoked potentials failed to predict a problem. Furthermore, in both cases these palsies recovered spontaneously and the patients had no remaining deficits. It is thought that these two brachial plexus palsies were associated with inadequate support for the shoulders during long procedures done in the sitting position. We, therefore, recommend that careful attention be given to fully supporting the upper limbs at the elbow during sitting procedures. Although no obvious explanation for the SEP failing to forewarn of these neurological complications exists, it is possible that the anaesthetic technique (inhaled isoflurane) may have depressed the SEP sufficiently to mask any further changes when ischaemia occurred.

One of the most serious problems associated with surgery done in the sitting position is the occurrence of venous air embolism. Previous studies have reported an incidence between 5 and 50 per cent. ${ }^{16}$ In our group 60 per cent of those patients operated on in the sitting position experienced some degree of air embolism. ${ }^{17}$ With the exception of one patient who became hypertensive after air embolism, which responded to IV ephedrine, all of these patients were successfully managed with standard therapeutic manoeuvres, including discontinuation of nitrous oxide, aspiration of venous air, and flooding the surgical wound with saline. ${ }^{17}$

One patient in the sitting position developed extreme macroglossia in the immediate postoperative period and required reintubation. This swelling took 12 weeks to subside after debridement had been carried out in the operating room. ${ }^{5}$ This patient suffered a bilateral lingual vein thrombosis, which was probably due to extreme neck flexion in the sitting position. Although bilateral lingual vein thrombosis has not been reported before it has been suggested as a possible mechanism for postoperative oedema of the tongue. ${ }^{5}$ It should, therefore, be emphasized that extreme flexion might be associated with complications postoperatively, and that special care should be taken to position the patient so that surgical exposure is maximal without resorting to extreme degrees of flexion.

While it is clear that some of our problems were associated with the sitting position, it should be emphasized that the prone position is not free of problems. In our experience, patients operated upon prone experienced far greater blood loss than those done sitting $\left(38 \pm 9 \mathrm{ml} \cdot \mathrm{kg}^{-1}\right.$ vs $18 \pm 4 \mathrm{ml} \cdot \mathrm{kg}^{-1}$ ). Blood loss was far easier to control with the patient sitting, probably because of better venous drainage and superior surgical exposure. This is not peculiar to dwarfs but is more a feature of the sitting position. In one prone patient, continuous venous oozing was considered such a major problem that surgery could not adequately be completed. In this case, blood loss was extreme $\left(65 \mathrm{ml} \cdot \mathrm{kg}^{-1}\right)$.

One patient in the prone position became extubated spontaneously. This patient was tumed supine and reintubated with no further complications. This tube had become loose because of leaking of 
saliva and secretions over the ahesive tape which secured the tube. Since that incident we have secured our tubes using a waterproof adhesive plastic drape and supported endotracheal and ventilator tubing after turning the patient prone. One patient whilst prone also experienced venous air embolism. This position should offer protection from venous air embolism by eliminating the pressure gradient between wound and right atrium. However, as previously reported, ${ }^{18}$ venous air embolism can occur whilst prone, with diasterous consequences.

In conclusion, we have presented our experience in anaesthetizing 27 achondroplastic dwarfs for 36 procedures. We found no difficulty in airway management during induction, and found that weight was the best guide for assessing the size of the endotracheal tube. We experienced some difficulty in positioning the very small children in the sitting position as no commercial chair is available. We further believe that the brachial plexus palsies, macroglossia and brain stem infarction are associated with this positioning problem, and we have recommended how to best avoid these complications in the future. We have pointed out the advantages and disadvantages of the sitting and the prone position and recommend that because of our experience, extreme care be taken to avoid venous air embolism if the procedure is undertaken in the sitting position.

\section{References}

1 Editorial. Br Med J 1949; 402.

2 Rimoin DL, Hughes GN, Kaufman RL, Rosenzhal $R E$, McAlister WH, Silberberg $R$. Endochondral ossification of achondroplastic dwarfism. N Engl J Med 1970; 283: 728.

3 Walts $L F$, Finerman $G$, Wyatt GM. Anaesthesia for dwarfs and other patients of pathological small stature. Can Anaesth Soc J 1974; 22: 703.

4 Berryhill RE. Skin and bone disorders. In: Katz J, Benumof J, Kadis LB, eds. Anesthesia and Uncommon Diseases, 2nd ed. Saunders, Philadelphia, 1981.

5 Mayhew, J, Miner M, Katz J. Macroglossia in a 16 month child following a craniotomy. Anesthesiology 1985; 62: 683 .

6 Stokes DC, Phillips JA, Leonard CO et al. Respiratory complications of achondroplasia. J Pediatr 1983; 102: 534 .
7 Fremion AS, Gard BP, Kalsbeck J. Apnea as the sole manifestation of cord compression in achondroplasia. J Pediatr 1984; 104: 398-401.

8 Pauli RM, Scott CI, Wassman ER et al. Apnea and sudden death in infants with achondroplasia. J Pediatr 1984; 104: 342.

9 Vogel A, Osborne RL. Lesions of the spinal cord (transverse myelopathy) in achondroplasia. Arch Neurol Psych 1949; 61: 644.

10 Yang SS, Corbett DP, Brough AJ, Heidelberger KP, Berstein J. Upper cervical myelopathy in achondroplasia. Am J Clin Path 1977; 68: 68-72.

II Mather JS. Impossible direct laryngoscopy in achondroplasia. Anaesthesia 1966; 21: 244.

12 Hitselberger WE, House WSA. Warning regarding the sitting position for acoustic tumour surgery. Arch Otolaryngol 1980; 106: 69.

13 Mahla ME, Long DM, McKennett J, Green C, $M c P h e r s o n R W$. Detection of brachial plexus dysfunction by somatosensory evoked potential monitoring. A report of two cases. Anesthesiology 1984; $60: 248$.

14 McPherson RW, North RB, Udvarhelyi GB. Rosenbaum $A E$. Midgrating disc complicating spinal decompression in an achondroplastic dwarf: intraoperative demonstration of spinal cord compression by somatosensory evoked potentials. Anesthesiology 1984; $61: 764$.

15 McPherson RW, Szymanski J, Rogers MC. Somatosensory evoked potential changes in positionrelated brain stem ischemia. Anesthesiology 1984; 61: 88-90.

16 Cucchiara RF, Bowers B. Air embolus in children undergoing suboccipital craniectomy. Anesthesiology 1982; 57: 338.

17 Katz $J$, Mayhew $J$. Air embolism in the achondroplastic dwarf. Anesthesiology 1985 (in press).

18 Shenkin $H N$, Galdfedder $P$. Air embolism from exposure of posterior cranial fossa in prone position. JAMA 1969; 210: 726. 


\section{Résumé}

Au cours de trois dernières années, 36 anesthésies ont été administrées à 27 patients atteint nanisme achondroplasique. Vingt quatre patients ont subi une crâniectomie pour sténose du foramen occipital. Seize de ces opérations ont été accomplies dans une position assise avec neuf incidents d'embolies gazeuse, tous survenant chez des patients ágés de moins de 12 ans.

Six complications majeures sont survenues: deux infarcisment de la moelle épinière au niveau de C-1, deux plexus brachial, une macroglossie sévère, et une extubation accidentelle.

L'accès intraveineux du patient avec un nanisme achondroplasique est difficile à cause de l'excès de peau et de tissus sous-cutané.

La conduite de maintien des voies aériennes et la laryngoscopie n'étaient pas difficile et on a trouvé que la grosseur du tube endotrachéal est mieux prédite par le poids du patient plûtot que son âge.

Les pertes sanguines ont été de $38 \pm 9 \mathrm{ml} \cdot \mathrm{kg}^{-1}$ en position couchée $(n=8)$ et $18 \pm 4 \mathrm{ml} \cdot \mathrm{kg}^{-1}$ en position assise $(n=16)$, et était en relation avec la position chirurgicale plutôt qu'au nanisme.

Nos données indiquent que les complications survien. nent plus fréquemment en position assise celles ci sont dangeureuses et toutes les précautions doivent être prises afin d'éviter leur survenue. 